\title{
Agrietar el capitalismo: el hacer contra el trabajo
}

DOI: https://doi.org/10.32870/

eees.v21i60.293

Juan Antonio Castañeda Arellano•

Para el capitalismo el mundo no es más que un enorme objeto para satisfacer su apetito: una gran mamadera, una gran manzana, un pecho opulento. El hombre se ha convertido en lactante eternamente expectante y eternamente frustrado: Erich Fromm.

Espero que la revisión crítica de este libro contribuya a una discusión para un acercamiento al debate que no sea papanatismo pseudo-profesoral, sino fresco viento que oree esta cultura nuestra que apesta a cárcel y a cloroformo... Yo tengo un enorme respeto por las personas, no por sus creencias. Hay que adquirir el derecho de decir a las gentes lo que no quieren oír. Es decir, si queremos entendernos verdaderamente, tenemos primero que contradecirnos. La verdad es hija de la discusión, no de la simpatía. A eso invita el libro de Holloway.

Confieso que la presente reseña solo agrega algunos comentarios, algunas ideas, muy pocas, que pretenden enchufarse desde mi balbuceante lectura y subjetividad. Quiero con rabia. Busco que el presente libro y que sus palabras, que son flores, son frutos, se conviertan en actos por la transformación de la sociedad infame donde John Holloway, 20I I, Agrietar el capitalismo: el habitamos. La búsqueda de hacer contra el trabajo, Benemérita Universidad de Puebla, México.

Espiral, Estudios sobre Estado y Sociedad

Vol. XxI No. $60 \sqcup$ Mayo / Agosto de 2014 
Juan Antonio Castañeda Arellano

lo deseado, la necesidad de tener una esperanza para vivir humanamente, lo que cada quien desea, pero que todos necesitamos para sentirnos vivos... En fin, Holloway escribe un esperanzado poema del pensamiento.

Estoy obligado, es mi deber manifestar que yo aquí únicamente recojo las tesis de Holloway; que intento comprender y me cuesta trabajo entenderlas, y si no las comprendo finjo hacerlo. Tengo que decir que solamente coloco algunas comas, puntos y digresiones que posiblemente distorsionan el texto. De ahí que ruegue al lector no fiarse demasiado de mí y, mejor, mucho mejor, leer el libro. Por ello sugiero brincarse esta reseña, que puede ocasionar molestias. Para los que la lean, conténtense con saber que estas son meramente notas, flashazos de una lectura fragmentada. Recuerden que esta es meramente mi mirada y que desde este momento he hecho la advertencia.

Como no aspiro a una existencia normal y rutinaria, y tengo conflictos entre mi pensamiento racional y mi naturaleza primitiva, voy camino a escapar a la cumbre más alta sin oxigeno. Son mis entresijos y obsesiones los propios de una persona en busca de la libertad, consciente de que el capitalismo es una realidad viva y esa es el área que se ha de derrumbar, esa cumbre que nadie ha escalado todavía.

Dejar de flotar, zambullirse, discurrir, sumergirse, encontrar lo claro-oscuro es el recorrido de la vida. Como neurótico, maníaco, esquizofrénico, utópico, soñador (el paraíso de los perturbados) las tesis de Holloway resuenan en mi cabeza y son un oasis, un ancla ante la amenaza del inminente naufragio social. Él huye de la burguesía, piensa, escribe, toma posición, se define, y a mí me ayuda a aliviar esta paradoja: odio la normalidad y la persigo, desprecio a los capitalistas y los envidio. Caduco sistema. Oh vida, cómo te he temido. Oh seres burgueses deshumanizados, cómo os he aborrecido; cómo he sufrido y pensado con sus empellones, con vuestras palabras que interrumpen mis 
Agrietar el capitalismo: el hacer contra el trabajo

pensamientos. Hemos sido envilecidos por vosotros; olíais mal; cuánta corrupción e injusticia, cuantas mentiras, enredos, volubilidades y servilismo y explotación... entre la vigilia y el sueño entremezclados en este país que cada vez más es un país sin primaveras.

Ubicarse en la ignorancia docta permite oponer una reflexión que ayuda a vivir, contribuye a salir de la experiencia nativa, entender que la vida siempre recomienza, un aspecto plural de la verdad, que cada situación es estructuralmente polisémica y que hay que superar la brecha entre razón e imaginación. En menos palabras, no se trata de administrar, reformar, contemplar o solo analizar, sino de expresar, accionar, agrietar, aunque sea de manera titubeante e incompleta, la vida social en su desarrollo, en sus desviaciones y detenciones. Un recorrido que no es seguro, que se vive día con día y que saca toda su intensidad de esto, de esta realidad que es precaria.

En la ignorancia docta hay un desarrollo tensional: cada situación y cada forma social es una composición de elementos heterogéneos que se articulan entre sí en dosis variables; el espíritu divaga en muchas manifestaciones; considerando incluso los aspectos supuestamente más serios, tiene lugar lo lúdico, y tomando en cuenta que la locura tiene su parte en las obras u organismos sociales que marcan el compás de las historias humanas, con lucidez y acaso con realismo, nos conformamos con seguir las huellas de esta situación en zigzag, característica de nuestra condición humana. Reconocer este estado de hecho no es mostrar la abdicación del espíritu, sino por el contrario apreciar la "lógica dinámica de los contrarios" que constituyen tanto las microcreaciones como las grandes obras de la cultura. Ese es precisamente el espíritu de la ignorancia docta, espíritu del politeísmo que se niega a decidir en la efervescencia de la vida social, espíritu de lo trágico que no se siente con el derecho para reducir las aporías estructurales del acto mundano. 
Juan Antonio Castañeda Arellano

Sin duda, es peligroso saber todo sobre la realidad. Por lo demás, podemos señalar que con base en esta pretensión se establecen las inquisiciones y se levantan las hogueras. No hay una sola realidad, sino diferentes maneras de percibirla. No nos preguntemos qué es "la forma". Es como si le preguntara al ciempiés como hace para caminar con tantas extremidades.

Es tanto el silencio, la servidumbre, la explotación sobre el planeta tierra que los astros se apagan poco apoco. En nuestro corazón llevamos nuestra nostalgia y una gran sed por lo imposible-posible. El corazón es una raíz de la que crece y crece la persona, una morada de la esperanza infinita y el enamoramiento por una sociedad mejor. Parece milagro que permanezcamos vivos, vivos todavía en un sistema inhumano, frío, en un hoyo injusto, desierto en medio de las estrellas y la luz. En el caos, donde los planetas estallan, donde la vorágine ardiente gira como torbellino, vivimos aún muy complacientemente, alegremente. Pero este libro nos mueve, nos cambia, nos entrega a un trabajo poderoso. Aquí estamos pensando.

Comparto plenamente las treinta y dos tesis de Holloway, algunas me parecen claras, otras se me dificultan y en otras requiero apoyo para su comprensión. Y como él, también lanzo un alarido de alegría rabiosa. Yo lo he estado haciendo mientras leo el texto en que se propone hacer el mundo de nuevo. Una explosión de furia alegre. Tiempo de coraje, enojo y celebración. El libro constituye una grieta temporal, quizá por unas horas, es una rendija de claridad, como un relámpago que ilumina un mundo diferente, un hacer diferente, un mundo creado, pensado y reflexionado con ilusiones utópicas y no utópicas, preocupaciones en aras de edificar una sociedad nueva sin subordinaciones, libre de restricciones, ni servidumbres ideológicas. Un mundo que podemos crear. Y lo hacemos. El mundo que todavía no existe. Es un enclave liberado o zona autónoma tempo- 
Agrietar el capitalismo: el hacer contra el trabajo

raria, un levantamiento, una subversión, es desesperanzaesperanzada, anárquica, agridulce, sabrosa e hiriente. Es una insurrección.

Agrietar el capitalismo lo he estado digiriendo con mis deficiencias teóricas en noches tranquilas de primavera cuando la sangre se altera, el calor crece y el agua escasea. He intercambiado dudas, inquietudes en conversaciones con compañeros que rememoramos las rebeliones e insurrecciones y acontecimientos de nuestro pueblo como 1968, Rubén Jaramillo, el ataque al cuartel Madera en ese legendario 23 de septiembre, las luchas de los maestros, de ferrocarrileros, mineros, la guerra sucia del 70 y el 80, la lucha del Frente Estudiantil Revolucionario FER, que se convirtió en un experimento de insurrección en Guadalajara y las actuales luchas de zapatistas, mineros, electricistas, campesinos, colonos que liberan una alegría y creatividad.

Sin duda, las viejas certezas revolucionarias han desaparecido. Ya no podemos proclamar con confianza que la victoria es inevitable. Aceptemos que se vive en un mundo de incertidumbre y confusión. Pero podemos hallar una forma de comprender nuestra incertidumbre, desesperanza y confusión. La cuestión central lo señala bien el autor: es la conciencia y la falta de conciencia. Pero solo de los desesperanzados puede lograrse la esperanza, algo así lo dice Horkheimer. La libertad es una aire habitual, sin perfumes exóticos, que se respira junto con el oxigeno sin pensarlo, pero conscientes de que existe.

Romper, queremos romper. Queremos crear un mundo diferente, ahora. Nada más común, nada más obvio, nada más sencillo, nada más difícil. 
Juan Antonio Castañeda Arellano

Existe una urgencia, una emergencia, una necesidad cada vez más apremiante de negar al capitalismo, este modelo criminal, infame, indigno y explotador. Ya es hora de aprender el nuevo lenguaje de una nueva lucha. El método, es el método de la grieta, el método sin puertas, sin ventanas, sin muros a cielo abierto. Es el método a construir minando, resistiendo, cavando, explorando, agrietando... Y en esta búsqueda la dignidad es el arma central contra un mundo en descomposición. Las grietas son las exploraciones en una antipolítica de la dignidad; comprendiendo que una grieta separa un memento de dominación de la creación de otras relaciones en que la alegría, la risa, abren paso a través de la seriedad del mundo de la dominación y de la sumisión, y NO a la risa complaciente y simuladora, NO la risa individual en soledad, sino una risa colectiva que se expanda hacia otro horizonte y lugar. La risa como principio revolucionario. En donde podemos y queremos y estamos haciendo otra cosa.

Lo importante es no trazar líneas divisorias, sino ver las líneas de continuidad. Una lógica diferente, una construcción alternativa, innovadora. Una lógica con humanidad, decencia, dignidad. La dignidad no nos esperará, la grieta es una insubordinación del aquí y el ahora, no un proyecto para el mañana. No se trata de un después de la revolución añorada y deseada, sino de un aquí y ahora.

Las grietas comienzan con un NO, a partir del cual crece la dignidad, una negación-y-creación. Una grieta es una creación perfectamente común de un espacio o momento en el que afirmamos un modo diferente de hacer. Las grietas rompen dimensiones, rompen la dimensionalidad, ya que el hacer disuelve la homogeneización del tiempo. Disuelve la totalidad, la síntesis, el valor. ¡Rehusar-y-crear! ¡Rehusary-crear! Eso, para los que luchan por un mundo diferente es seguir a Moisés y a los profetas; salvo que no tenemos ni queremos ningún profeta, solo nos tenemos a nosotros mismos. La cuestión de las grietas es que corren y pueden 
Agrietar el capitalismo: el hacer contra el trabajo

moverse en forma rápida e impredecible. Es la decisión de tomar un espacio o un momento en nuestras propias manos y estructurar nuestras vidas de acuerdo con nuestras propias decisiones. Eso sí, decididos a no subordinarnos y servir más. Esa es la ruptura y la ruptura comienza con el rechazo, con el NO.

El NO debe estar respaldado por otra mirada, por otra actitud, por otro hacer. Esta es la dignidad que puede llenar las grietas por el rechazo. El NO original no es un cierre, sino una apertura a una actividad diferente, a una visión en construcción; es el umbral a un contra mundo con una lógica alternativa y un lenguaje diferente. El NO se abre a un espacio-tiempo en el que tratemos de vivir como sujetos en lugar de como objetos; a constituirnos como seres humanos plenos y dignos. Estos son tiempos o espacios en los que afirmamos nuestra capacidad para decidir por nosotros mismos lo que deberíamos hacer, ya sea jugar, cantar, gritar, reír, contemplar la luna, el mar, cultivar la tierra de forma diferente...

La dignidad es el desarrollo de la potencia del poder del NO. Nuestro rechazo nos enfrenta con la oportunidad, la necesidad y la posibilidad de desarrollar nuestras propias capacidades. Lo importante es el movimiento, el moverse contra-y-más-allá: el negar-y-crear de quienes abandonaron la sumisión y la dominación del sistema capitalista. La dignidad, el movimiento de negar-y-crear, de tomar control de nuestras vidas, no es una cuestión simple. Es -como lo dice muy bien el hacedor de este libro- un líquido oscuro saliendo a borbotones de un lago de posibilidades. Otorgarle solidez positiva a lo que solo puede ser un movimiento de rechazo, creación y exploración nos puede llevar fácilmente a la desilusión.

Hay que entender que las grietas siempre son preguntas, nunca respuestas. Es importante no idealizar las grietas o adjudicarles una potencia positiva que no poseen. Sin 
Juan Antonio Castañeda Arellano

embargo, es allí desde donde comenzamos; desde las grietas, desde esas perforaciones, fisuras, ranuras, las cismas, los espacios de negación-y-creación insurreccionales. Partimos de lo particular, no de la totalidad. Partimos de nuestra inadecuación al mundo, de esta realidad asfixiante, de la multiplicidad de las rebeliones, rebeldías, dignidades, grietas particulares; no partimos de la gran lucha, la gran rebelión o revolución, no del sistema de dominación. Partimos del estar encabronados, rabiosos, enojados e intentando crear algo más, otra cosa; porque ahí es donde estamos. Quizá es un lugar extraño, raro, incierto, estamos buscando la esperanza en una noche claro-oscura. Holloway teoriza, está teorizando la esperanza-contra-toda-esperanza, y nos dice que esta es la única pregunta teórica que queda planteada para la humanidad.

La pregunta es básica, es elemental. Queremos crear un mundo diferente ahora. Hay urgencia en todo esto. ¡YA BASTA! Ya estamos hartos de vivir en un mundo de explotación, violencia, hambre e impunidad. "Estamos hasta la madre"; "no más sangre", no más humillación. También estamos hartos de reproducir el sistema capitalista. Ahora existe una urgencia. La urgencia que nos dicta el tiempo mismo (tal vez a destiempo), pero no va a haber otro tiempo. Es evidente que nosotros, los seres humanos, estamos destruyendo las condiciones naturales de nuestra existencia. Ya no tiene más sentido hablar de la paciencia como una virtud revolucionaria ni hablar de la revolución del futuro. ¿De qué futuro? Necesitamos la revolución ahora, aquí y ahora. Es tan absurdo, tan necesario, tan obvio. No podemos ser tan claros que no se entienda. Estamos encerrados, atrapados por el dinero, por la violencia, atrapados por la lógica de la cohesión social de este sistema criminal. Somos nosotros quienes creamos la prisión. El hecho de que construimos nuestra propia prisión es tanto una fuente de esperanza como una de profunda depresión. Pero el hecho de edificar 
Agrietar el capitalismo: el hacer contra el trabajo

el mundo que nos mantiene atrapados significa que también podemos deshacerlo.

Entre la tensión y la rebelión. Todas las relaciones sociales son campos de batalla activos; antagonismos vivos. El hacer-otro está reprimido; otro no extinto. Nuestro poder hacer tiene una dinámica: es un movimiento constante en contra-y-más-allá de lo que es. Nuestro punto de partida es la ruptura. Sin embargo, la ruptura no es estable, sino fugaz: su existencia como ruptura depende de su movimiento. Encarna un constante empujar hacia afuera; un constante impulso contra esta sociedad de relaciones ensuciadas, de encierros y rigideces que frustran nuestro hacer. De ahí que el cambio no puede provenir del hacer aislado, sino solo de los flujos, de las confluencias, del movimiento de las grietas que irrumpen con fuerza a lo largo de las venas ocultas de la furia. Y en este andar no existen las certezas, y, si las hubiese, serían encierros que habrían de ser quebrados.

La única seguridad que tenemos es que los únicos caminos son los que hacemos en libertad. Agrietar, agujerear, luchar no solo contra, sino en contra-y-más-allá es siempre cruzar un umbral hacia un horizonte, un más allá, una suerte de contramundo; imaginando un mundo diferente, actuando en un mundo diverso; una apuesta atrevida, experimental. Es el traspasar un umbral hacia un mundo que podía -o no- llegar a existir; un mundo que no existe y la esperanza de que realizándolo podemos verdaderamente dale vida o, más bien, sabiendo que este es el único camino para darle vida; es un faro de dignidad que brilla en una noche oscura; vibraciones de esperanzas incumplidas, promesas de un futuro posible; un sabor de libertad; construyendo las cosas con ironía, con humor, con el juego y con una profunda revolución que identifique la libertad con la imaginación. Por ese camino se llega al paraíso terrenal, contradictorio, erótico, misterioso, enigmático, fraternal y complejo. Construir 
Juan Antonio Castañeda Arellano

un espacio en el que se puedan alojar tiempos y espacios diversos. Tiempos divergentes convergentes y paralelos.

Estamos en el umbral de un mundo culturalmente insatisfecho y diverso. El capitalismo es el umbral de la tragedia: el reconocimiento del valor de la derrota y la hermandad con el fracaso, que es la regla, y no la excepción, de lo humano. Recuerdo que el escritor Faulkner hace decir a uno de sus personajes "[...] todo es presente. ¿Entiendes? El ayer solo terminará mañana y el mañana comenzó hace diez mil años". La memoria es un acto de supervivencia creativa. Debemos imaginar el pasado para que el futuro, cuando llegue, también pueda ser recordado, evitando así la muerte de los eternamente olvidados. Todo está a punto de ser otra cosa. Recordar el futuro, imaginar el pasado es irreversible, y el futuro incierto. Las personas se quedan solo con el escenario del ahora, si es que quieren representar el pasado y el futuro. Comprendemos entonces que el pasado depende de nuestra memoria aquí y ahora. La memoria y el deseo son nuestra imaginación presente: este es el horizonte de nuestros constantes descubrimientos y este es el viaje que debemos renovar cada día agrietando el capitalismo. Para eso estamos aquí leyendo este libro.

Ante un orden global que consagra la libertad de las cosas pero rehúsa la libertad de las personas, ¿a dónde escapar a tantas contradicciones? Sobran playas, cerros y pirámides, y la facilidad, lo accesible, niega nuestra vocación de desastre. ¿Democracia? Para transar. ¿Tranquilidad? Para morirse de aburrido. ¿Historia? No-realidad, sino apenas, pobre remedio para la realidad. ¿Qué nos queda? Agrietar el capitalismo: ese es el camino.

La imaginación revela el poder del deseo y también la voluntad de cambio. La liberación a través de la imaginación de los espacios cotidianos. Liberación de energías, necesidad y libre albedrio. Ante la fantasía del espacio cerrado, hay que crear cielos no artificiales para sentirse a salvo de la 
Agrietar el capitalismo: el hacer contra el trabajo

podredumbre, de la explotación del sistema capitalista. Hay que pasar del aburrimiento a la indignación.

La utopía es el lugar que no es, porque no hay lugar en el tiempo. Hay que estar condenados a agrietar la sociedad infame que habitamos. En ella no se puede poseer nada, salvo el sueño en el que viven las mayorías y del que pocos se atreven a despertar. La lucha contra el Estado capitalista, más que contra la opresión, es una lucha contra la fatalidad, contra la indiferencia, la rutina, la falta de imaginación, la ignorancia y el designio incontrolado de las cosas.

La dignidad es el arma en contra de un mundo de destrucción. En toda rebelión hay un profundo dilema. La rebelión es siempre irracional si la juzgamos desde la racionalidad dominante. Queremos romper: esa es la idea de la grieta que se expresa primeramente y de manera constante en el planteamiento de Holloway. No debemos perder de vista esa constante. Se trata de la ruptura. Queremos romper no solo para hacer las cosas un poco mejor, queremos quebrar la dinámica infame de un sistema que nos está destruyendo. En todos lados tenemos que hacer las cosas de una manera diferente. No tiene sentido plantearse obedecer la ley como una cuestión de principios, aunque las consecuencias prácticas de cualquier acción en particular siempre dependerán del contexto.

Tenemos claro que la violencia no es parte de la sociedad que queremos crear. La violencia no es un terreno neutral, sino el terreno de las fuerzas de dominación. Ella nos introduce en las relaciones y formas sociales de conducta que repudiamos: las estructuras jerárquicas dominadas por los hombres. La dignidad es nuestro terreno y la violencia es la negación de la dignidad, venga de donde venga. No hay pureza, no hay respuestas de antemano. La única respuesta, entonces, es pensar en términos de formas intersticiales no estables; o sea, grietas.

Lecturas Críticas $\&$ No. 60 
Juan Antonio Castañeda Arellano

Las grietas chocan contra nosotros mismos; es decir, creamos nuestras grietas, nuestros espacios de dignidad y ellas son inmediatamente amenazadas por el mundo que nos rodea. Pero este mundo no es solo exterior: lo llevamos en nuestro interior. Construimos nuestra comunidad autónoma en el barrio, el ejido, en la selva lacandona. Creamos nuestro hacer en la escuela, la universidad, la fábrica, el taller o sindicato. Vamos a una fiesta que dura toda la noche en nuestra colonia. Vamos al café, al parque, en compañía de un libro de poemas o novela para recrearlo. Decimos: "aquí no, aquí no aceptamos el dominio, a la chingada el dominio del sistema, aquí haremos otra cosa, aquí creamos un espacio de dignidad, horizontalidad, amor, libertad, autonomía”. Pero, obviamente no es tan simple; aunque así le cortamos una rebanada de infamia al sistema, ínfima, pero lo mutilamos.

Nuestras grietas, nuestros espacios no son puros. Tratamos de romper con la sociedad capitalista, pero nuestra ruptura todavía lleva consigo sus marcas de nacimiento, nuestra historia, nuestra formación, nuestro ambiente enrarecido. No somos sujetos puros, por muy rebeldes que podamos ser. Las grietas, como espacios de liberación, y como estructuras dolorosas, también se abren en nuestro interior. Nuestra lucha es una en la que puede haber una verdadera unión de grietas. Lo que queremos es una conexión social basada en la confianza, la solidaridad, la generosidad, el regalo; en lugar de la espera, de la pasividad.

Señala el autor que el trabajo abstracto encierra nuestros cuerpos y nuestras mentes; que la abstracción del hacer en el trabajo es la homogeneización del tiempo y que el hacer es la crisis del trabajo abstracto. El trabajo, como trabajo alienado, es una separación del nosotros respecto a nosotros mismos, una ruptura en pedazos entre nosotros y nuestra actividad. Es a través de nuestro trabajo enajenado que producimos a nuestro amo. 
Agrietar el capitalismo: el hacer contra el trabajo

Nuestras dignidades son siempre un moviéndose-encontra, un explorando-más-allá, en lo que arriesgamos nuestras vidas para romper con lo que rechazamos y hacerlo con certidumbre, creando algo a lo que aspiramos con incertidumbre. "No seguiré la lógica del capital, haré otra cosa". Nuestro otro-hacer es el acto de rebelión, un ir en-contra-y-más-allá.

La conformidad nos dice una y otra vez "corre si quieres, ésta es una sociedad libre", pero no hay escape, no hay escape, no hay huida, no hay evasión; un choque real constante. Nos arrojamos una y otra vez contra las paredes que avanzan y nos herimos. Gritamos hasta que el hielo se rompe y luego contemplamos mientras el hielo se congela de nuevo. Nuestras grietas existen al borde de la imposibilidad. Este trajinar en la duda, el escepticismo, al borde del desencanto, es lo que significa la dignidad en una sociedad basada en su negación. El mundo está lleno de inadecuaciones, de personas que dicen "no nos adecuamos y no nos adecuaremos jamás". Son locuras que empujan a un mundo diferente. Estas dignidades que no esperarán hasta después de la revolución o el paraíso. Empezamos desde el impulso de rabia, de esperanza y de creatividad. Tratamos de romper las restricciones de la sociedad que nos oprime, de desbordar la dominación que nos sofoca para crear algo más. No es una cuestión de pureza, pues toda grieta reproducirá lo agrietado en su interior. Es una cuestión de movimiento, de dirección. El movimiento es lo que importa. La posibilidad de las grietas está en su movimiento.

"La rebelión es inseparable de la obediencia, como la inadecuación lo es de la adecuación." En Agrietar el capitalismo: el hacer contra el trabajo John Holloway formula preguntas que nos obligan a hacerlas nuestras: ¿Qué hacemos? ¿Cómo dejamos de hacer el capitalismo? ¿Cómo cambiamos el mundo? ¿Cómo detenemos esta horrible destrucción que nos rodea? ¿Cómo podemos, en un mundo 
Juan Antonio Castañeda Arellano

en el que las personas son personificaciones de su función social, pensar en cambiar el mundo de forma radical? Si estamos atrapados en roles generados por el capitalismo, ¿cómo podemos pensar en romper el molde de las relaciones sociales formadas por estos roles? Estas son unas interrogantes constantes mientras leemos el texto y nos encontramos con otras interrogantes y más, y otras más. Son las preguntas que obsesivamente y desesperadamente nos hacemos a diario, en la cotidianeidad, en los lugares en los que nos encontramos.

Entendemos que la conciencia potencia la razón y por tanto aprendemos a rebelarnos contra la sinrazón, es decir, las personas racionales no lo son solo porque se compartan racionalmente, sino porque luchan por vivir en una sociedad racional y razonable, porque luchan por que no predominen los dogmas irracionales, las supersticiones, los fanatismos; aquello que va contra la razón. De modo que la razón es una muestra de convivencia, pero también una fuente de disidencia y de rebelión. El argumento de John Holloway es muy sencillo: nosotros hacemos el capitalismo, nosotros debemos dejar de hacerlo y hacer algo más. Significa poner el hacer contra el trabajo abstracto: esto es lo que debemos y podemos hacer; esto es lo que ya debemos estar haciendo. El argumento es simple; sin embargo, tiene sus complejidades. El trabajo abstracto teje un mundo complejo, y es importante reconocer la complejidad de este tejido para comprender la unidad subyacente de luchas aparentemente no relacionadas contra el mundo tal como existe, y ver qué es lo que estamos tratando de desenredar y de tejer en forma diferente.

El autor que estoy reseñando nos dice una y otra vez que uno de los elementos más sutiles, y sin embargo más poderosos, de la telaraña que tejemos para atraparnos es que el trabajo abstracto crea el reloj. El reloj habla de la duración, de la homogeneización del tiempo. Desde la pers- 
Agrietar el capitalismo: el hacer contra el trabajo

pectiva del reloj un minuto es lo mismo que el siguiente. El reloj camina y camina, cuantificando el tiempo, contando los minutos de felicidad de la misma forma que los minutos de desesperación, proyectando el pasado en el futuro. Para el reloj mañana será lo mismo que hoy o que ayer. Para el maldito reloj, la única revolución concebible es la que da vueltas y vueltas y vueltas, sin cambiar nada. Este es el tiempo de la duración. El tiempo de la separación del tiempo de nuestro hacer. Los relojes no solo representan la disciplina laboral, no solo la puntualidad, sino toda una forma de vivir y comprender el mundo. El tiempo del reloj, el tiempo de la duración, es el tiempo de separar el sujeto del objeto; la constitución de la existencia al hacer de lo hecho. Creamos algo y la cosa que creamos se separa de nosotros. El tiempo-cosa es la negación del tiempo-persona, el tiempoobjeto. El tiempo-reloj es el tiempo de nuestra impotencia, de nuestra subordinación a las cosas. Es el tiempo no de la vida, sino de la supervivencia, del lento transcurrir día a tras día, el tiempo del aburrimiento, del tedio.

Creamos el mundo que nos está matando; y si lo creamos, entonces, podemos dejar de crearlo para hacer, en cambio, otra cosa. Somos los sujetos creados por el capitalismo. Es obvio que las personificaciones nos limitan. En tanto que soy un maestro universitario hago determinadas cosas y no otras. Nuestra identidad es limitada y también clasificable. Dentro de mis límites como profesor universitario caigo en una determinada clase, la clase de los docentes universitarios. El mundo de la personificación es un mundo ordenado, un mundo que puede ser clasificado, un mundo en el que las personas cumplen sus funciones sociales, un mundo que puede ser comprendido en términos funcionalistas, un mundo en el que la revolución no tienen lugar.

Todo lo mencionado anteriormente, lo hago en serio y con dulce rabia, pero sin la seriedad, la solemnidad y esa rigidez acostumbrada a medir los frutos del trabajo por el 
Juan Antonio Castañeda Arellano

aburrimiento que este proporciona. En fin, la diferencia no es algo para temer, sino algo para trabajar. Como sabemos, aunque este mundo sea inhabitable hay que vivir en él; aunque es inconcebible, tenemos que reflexionar sobre él. En este caso, Agrietar el capitalismo... no es un trabajo común, una reflexión simplista, se trata de una brillante y compleja propuesta de pensar y hacer otra cosa que no es menor; de un proceso metanoico contrario a la actitud paranoica normal. Pero con esto espero acercarme -sin desear violarla- a la centralidad clandestina que constituye el libro de Holloway.

Finalmente, para quienes deseen realmente profundizar en él, no hay más que abordarlo. No hay notas a pie de página ni al final. Aquí no indico -posiblemente- las tesis más importantes, solo propongo que sea leído y analizado; que esta mezcla de reflexiones propuestas aquí impulsen a adentrarse en el libro. Holloway nos ofrece los medios intelectuales para transformar la mirada que dirigimos sobre el mundo social capitalista, así como sobre nosotros mismos. En tal sentido, puede ser considerado el libro como un socioanálisis que nos permite comprender cosas a la vez personales y generales, los juegos que jugamos, los intereses que en ellos invertimos y las resistencias que oponemos al reconocimiento de todo lo que hasta entonces ha sido confiado al área de lo desconocido.

Lo que sigue es pensar en la armonía conflictiva de todo conocimiento. Sin duda, esta duda no se refiere tanto a los hechos mismos como a la exagerada creencia que se tiene de ellos. Así lo creo. Mis reflexiones pueden parecer que no tienen lugar en tiempo preciso, pero no son como las novelas de Proust (En busca del tiempo perdido); desde luego que podemos darles una ubicación en función de nuestros fantasmas y de nuestras fantasías; aunque más que nada sirven para actualizar y despertar ecos. Antes que nada, pueden ser matrices infecundas para el lector que puede 
Agrietar el capitalismo: el hacer contra el trabajo

imaginar a su antojo paisajes, situaciones concretas y situaciones y acontecimientos inusitados: el trabajo del artista se limita a "dejar piedras en el camino" para esos vagabundeos intelectuales. Holloway agrieta, perturba, sacude moviliza, estruja la aborrecida estructura capitalista. Esto es más o menos lo que se propone con su trabajo. No evita referirse a situaciones concretas o históricas; lo hace con el conocimiento, la pasión, el amor, el sabor; lo hace con la rabia, con el humor, que templa un poco la frescura lógica; sin embargo, es posible que cada quien, en base a las situaciones que vive, analiza o sueña, elabore su propia construcción según los lineamientos propuestos.

Aclaro que esta invitación a la lectura del libro no quiso incluir un aparato teórico metodológico organizado y sistemático que llevara a la repetición, la esterilidad y a las formulaciones que recetan lo que los jóvenes llaman "la neta". No tiene ni una pizca de aparato estadístico o seudoeconómico. En este contexto, me atrevo a proponer las sólidas tesis de Holloway, junto a algunas ideas y digresiones mías; producto de un acercamiento abierto a la interpelación, la cual conviene leer o releer, si pareciera pertinente. Tengo la inmodestia, la indecencia de creer que se trata de esbozos congruentes con un nuevo arte de pensar, que, más allá de la hilaridad que mi atrevimiento pudiera ocasionar, tengo la convicción de que está a punto de surgir ante nuestros ojos.

Lecturas Críticas \& No. 60 